\title{
Beliefs and practices in using misoprostol for induction of labour among obstetricians in Zimbabwe
}

\author{
M G Madziyire, ${ }^{1}$ MMed (O\&G); B Mateveke, ${ }^{2}$ MMed (O\&G); M F Gidiri, ${ }^{1}$ FRCOG \\ ${ }^{1}$ Department of Obstetrics and Gynaecology, College of Health Sciences, University of Zimbabwe, Harare, Zimbabwe \\ ${ }^{2}$ Department of Obstetrics and Gynaecology, Harare Hospital, Harare, Zimbabwe
}

Corresponding author: M G Madziyire (gynaemadzi@y7mail.com)

Background. Misoprostol is commonly used for induction of labour in term pregnancy. There are different routes and dosing schedules for administering the drug.

Objectives. To describe the prescribing pattern (dose, route, duration), beliefs and factors affecting use of misoprostol for inducing term pregnancy among practising obstetricians in Zimbabwe.

Methods. A cross-sectional descriptive survey was undertaken among practising obstetricians in Zimbabwe. A questionnaire was sent as an email, WhatsApp or short message service (SMS, or text) web link to all practising obstetricians in Zimbabwe using the SurveyMonkey online tool. All consenting practitioners were requested to respond online. The responses were analysed using the SurveyMonkey software.

Results. There were 52 responses from the 63 questionnaires, a response rate of $82.5 \%$. Seventy-six percent preferred oral misoprostol for induction of labour. The most common indication for induction was prolonged pregnancy accounting for $58 \%$ of respondents. The largest group of the practitioners who responded (36\%) learnt their misoprostol dosing regimen from WHO/FIGO/NICE guidelines. A composite of highly variable dose regimens referred to as 'other regimens' was the dosing regimen preferred by $34 \%$ of respondents. Fiftyeight percent of practitioners used two cycles of misoprostol dosing before concluding that induction had failed and $52 \%$ would resort to caesarean section immediately if induction failed.

Conclusion. The results show marked heterogeneity in the dosing schedules employed by obstetricians for induction of labour with the majority not following standard misoprostol guidelines for labour induction.

S Afr J Obstet Gynaecol 2017;23(1):24-27. DOI:10.7196/SAJOG.2017.v23i1.1163

Misoprostol is a prostaglandin E1 analogue widely used for the induction of labour in term pregnancy because of its low cost and efficacy when compared with most methods of induction. ${ }^{[1]}$ Induction of labour was estimated to account for $9.6 \%$ of births during the World Health Organization (WHO) global survey on perinatal and maternal health. ${ }^{[2]}$ Different routes of administering misoprostol for the induction of labour have been employed with the oral route preferred because of ease of administration and a short half-life. ${ }^{[1,3]}$ A reduced caesarean section rate was reported with the dose of oral misoprostol of $20-25 \mu \mathrm{g}$ 2-hourly compared with vaginal dinoprostone. ${ }^{[1]}$ Oral misoprostol $50 \mu \mathrm{g}$ 4-hourly at up to 5 doses was also shown to be as safe and as effective as $25 \mu \mathrm{g}$ 4-hourly when administered vaginally at 5 doses. ${ }^{[4]}$ Various misoprostol induction regimens have been suggested and consequently clinicians have developed diverse prescribing patterns. Various professional bodies have produced recommended dosing regimens.

The WHO, International Federation of Gynecology and Obstetrics (FIGO) and the National Institute for Health and Care Excellence (NICE) guidelines recommend $20-25 \mu \mathrm{g}$ oral misoprostol 2-hourly and $25 \mu \mathrm{g}$ given vaginally every 6 hours. ${ }^{[2,5]}$ The oral titration regimen has emerged as the preferred regimen as it is less likely to cause uterine hyperstimulation. ${ }^{[1,6,7]}$ The guidelines are silent on issues such as maximum number of doses, breech presentation (if caesarean section is declined) or induction in multiple pregnancies. ${ }^{[2,8,9]}$

In Zimbabwe, the Ministry of Health and Child Care has adapted the WHO guidelines with the dosing regimen outlined above; however, various hospitals follow their own specific guidelines. Harare Central Hospital and Parirenyatwa Hospital, which are tertiary teaching hospitals, follow a titrated oral dose which differs according to parity and is outlined in Table 1.

The dosing in Table 1 is administered until onset of labour, or when $200 \mu \mathrm{g}$ misiprostol has been depleted. There is no instruction on the appropriate action if there is no response to the first cycle of dosing. A cycle of induction of labour is considered to be the doses required before or after completion of

Table 1. Recommended oral misoprostol regimen at Harare and Parirenyatwa hospitals

\begin{tabular}{lll}
\hline Parity & $\begin{array}{l}\text { Loading dose } \\
(\mathbf{m L})^{*}\end{array}$ & Hourly dose $(\mathbf{m L})^{*}$ \\
\hline 0 & 30 & 20 \\
$1-2$ & 20 & 15 \\
3 & 20 & 15 \\
$\geq 4$ & 15 & 15 \\
${ }^{*} 1 \mu \mathrm{g} / \mathrm{mL}$ misoprostol solution. &
\end{tabular}


a total dose of $200 \mu \mathrm{g}$ of misoprostol, whichever way it has been administered. This dosing schedule was created empirically by senior obstetricians in the unit based on their experience with misoprostol use.

\section{Methods}

A questionnaire was sent as either an email, WhatsApp or SMS/ text with a web link to all practising obstetricians in Zimbabwe using the SurveyMonkey online tool. All qualified and practising obstetricians who consented to take part in the survey were contacted. There were 65 registered obstetricians in Zimbabwe at the time of the study (April 2016) according to the Zimbabwe Society of Obstetricians and Gynaecologists (ZSOG) register. Permission to conduct the study was obtained from the ZSOG. Responses were analysed using the SurveyMonkey online analytical tool. The response on misoprostol dosing was open-ended requiring practitioners to write the actual dose they would prescribe for induction of labour. The investigators then categorised the responses according to similarities, or being part of a standard dosing regimen recommended by local or international practice guidelines. All oral doses were mainly in the form of misoprostol dissolved in water to make a $1 \mu \mathrm{g} / \mathrm{mL}$ solution. Table 2 shows the rationale of the dosing categories which were used for analysis.

\section{Results}

There were 52 responses from the 63 questionnaires, a response rate of $82.5 \%$. Two responses were incomplete and were removed from the final analysis. All respondents preferred misoprostol for induction of labour with $39(78 \%)$ preferring the oral route. The largest group of respondents (36\%) adapted their dosing schedule based on the WHO/FIGO/NICE guidelines.

A composite of variable dosing schedules referred to as 'other regimens' was the most common dosing schedule, followed by the departmental dosing guideline and the WHO/FIGO/NICE dosing guideline, across all parities. Ten practitioners (20\%) did not use misoprostol for $\geq$ para 4 .

\section{Discussion}

This study shows variable dosing schedules used for inducing labour in term pregnancy using misoprostol by obstetricians in Zimbabwe. The largest group of practitioners use dosing schedules which do not comply with any set guidelines - for example, the dosing schedule referred to as 'other regimens' comprised highly variable misoprostol regimens, which did not correspond with the main dosing categories selected for analysis (Table 2). The trend for practitioners with $<5$ years' experience to follow departmental guidelines (10 (50\%)) more than their colleagues with more years of experience (5 (30\%)) (Table 3) seems to imply that more experienced colleagues are more likely to depart from guidelines set for uniform practice in the public sector as experience gives them the latitude to use their own regimens. While $36 \%$ of practitioners claimed that they adapted their dosing regimen based on the WHO/FIGO/NICE guidelines, only 10 (20\%) practitioners used the regimen in actual practice. The fact that $42(84 \%)$ practitioners were either in part-time private practice or fulltime government/university practice does imply that they knew of these departmental guidelines.

The most common indication for inducing labour was prolonged pregnancy $(58 \%)$ (Table 4). This differs from a randomised controlled trial at Harare Hospital in 2013, which looked at factors associated with failed induction of labour with titrated oral misoprostol and found hypertensive disorders to be the commonest indication (38.1\%). ${ }^{[7]}$ The difference could be due to Harare Hospital being a tertiary centre for high-risk pregnancies and this would select out hypertensive disorders as a common cause of referral.

There is no agreed definition of failed induction of labour using misoprostol, mainly because practitioners have varied desired endpoints of the induction process. The choice of using failure of initiating labour after two cycles of misoprostol as failed induction is arbitrary, and probably chosen as obstetricians try to balance the increased risk of adverse maternal-fetal outcomes and unwarranted intervention.

It is noteworthy that a proportion of practitioners have calculated a dosing schedule which begins with $50 \mu \mathrm{g}$, then followed with 20 - $30 \mu \mathrm{g}$

\section{Table 2. Dosing categories}

\begin{tabular}{|c|c|}
\hline $\begin{array}{l}20 \text { - } 30 \mu \mathrm{g} \text { stat, } 15-20 \mu \mathrm{g} \text { hourly (oral) } \\
\text { (departmental regimen) }\end{array}$ & $\begin{array}{l}\text { This is the dosing schedule pinned up in the teaching maternity units of Harare and Parirenyatwa } \\
\text { hospitals where most of the obstetricians in Zimbabwe work or have passed through during their training. } \\
\text { The higher limit of the dose is recommended for the nulliparous and it is tailored down for women of } \\
\text { higher parity. }\end{array}$ \\
\hline $\begin{array}{l}20 \text { - } 25 \mu \mathrm{g} \text { 2-hourly (oral) (WHO/FIGO/ } \\
\text { NICE) }\end{array}$ & $\begin{array}{l}\text { This is the WHO/FIGO/NICE recommended dose for inducing a term pregnancy. The 'Essential Guide } \\
\text { to Management of Common Obstetric and Gynaecologic Conditions in Zimbabwe', produced by the } \\
\text { University of Zimbabwe, Department of Obstetrics and Gynaecology also recommends this regimen. } .^{[9]} \\
\text { The Ministry of Health and Child Care has also adopted this regimen and put it up on wall charts in } \\
\text { various maternity units in Zimbabwe. }\end{array}$ \\
\hline $50 \mu \mathrm{g} 4$ - 6-hourly (oral) & $\begin{array}{l}\text { The 'Essential Guide to Management of Common Obstetric and Gynaecologic Conditions in Zimbabwe', } \\
\text { produced by the University of Zimbabwe, Department of Obstetrics and Gynaecology recommends } 50 \mu \mathrm{g} \\
\text { 4-hourly of oral misoprostol or } 50 \mu \mathrm{g} \text { 6-hourly of vaginal misoprostol. }\end{array}$ \\
\hline $\begin{array}{l}50 \mu \mathrm{g} \text { stat, followed by } \\
15-30 \mu \mathrm{g} 1 \text { - 2-hourly (oral) }\end{array}$ & This was a common dosing range among the respondents. \\
\hline - $25 \mu$ g hourly (oral) & is was found to be preferred by up to 3 respondents. \\
\hline
\end{tabular}

Other regimens (oral)

This category comprised highly variable dosing regimens.

Vaginal

No use
Any vaginal dosing.

Those who would not administer misoprostol. 
RESEARCH

\begin{tabular}{|c|c|c|c|c|c|}
\hline Years in practice & $<5$ & $5-10$ & $11-20$ & $>20$ & Total, $n(\%)$ \\
\hline \multicolumn{6}{|l|}{ Sex } \\
\hline Female & 7 & 3 & 1 & 3 & $14(28)$ \\
\hline Male & 13 & 5 & 9 & 9 & $36(72)$ \\
\hline Total, $n(\%)$ & $20(40)$ & $8(16)$ & $10(20)$ & $12(24)$ & $50(100)$ \\
\hline \multicolumn{6}{|l|}{ Practice } \\
\hline Part-time ${ }^{*}$ & 11 & 6 & 8 & 6 & $31(62)$ \\
\hline Government practice & 7 & 1 & 2 & 1 & $11(22)$ \\
\hline Private practice & 2 & 1 & 0 & 5 & $8(16)$ \\
\hline Total & 20 & 8 & 10 & 12 & $50(100)$ \\
\hline \multicolumn{6}{|l|}{ Source } \\
\hline Departmental guidelines (Table 1) & 10 & 1 & 2 & 2 & $15(30)$ \\
\hline WHO/FIGO/NICE guidelines & 5 & 3 & 6 & 4 & $18(36)$ \\
\hline Experience & 2 & 1 & 0 & 4 & $7(14)$ \\
\hline Colleague & 1 & 2 & 1 & 1 & $5(10)$ \\
\hline Other & 2 & 1 & 1 & 1 & $5(10)$ \\
\hline Total & 20 & 8 & 10 & 12 & $50(100)$ \\
\hline \multicolumn{6}{|l|}{ Cycles } \\
\hline 2 cycles & 12 & 6 & 5 & 6 & $29(58)$ \\
\hline 1 cycle & 6 & 2 & 3 & 3 & $14(28)$ \\
\hline Other $(<1$ cycle or $>2$ cycles $)$ & 2 & 0 & 2 & 3 & $7(14)$ \\
\hline Total & 20 & 8 & 10 & 12 & $50(100)$ \\
\hline \multicolumn{6}{|l|}{ Cervical assessments } \\
\hline No & 4 & 0 & 1 & 0 & $5(10)$ \\
\hline Yes & 7 & 6 & 7 & 11 & $31(62)$ \\
\hline Sometimes & 9 & 2 & 2 & 1 & $14(28)$ \\
\hline Total & 20 & 8 & 10 & 12 & $50(100)$ \\
\hline \multicolumn{6}{|l|}{ Route of administration } \\
\hline Oral & 18 & 5 & 8 & 8 & $39(78)$ \\
\hline Vaginal & 2 & 3 & 2 & 4 & $11(22)$ \\
\hline Total & 20 & 8 & 10 & 12 & $50(100)$ \\
\hline
\end{tabular}

Table 4. Common indication for induction $(N=50)$

\begin{tabular}{ll}
\hline Answer choices & Responses, $\boldsymbol{n}$ (\%) \\
\hline Hypertensive disorders & $21(42)$ \\
Ruptured membranes & 0 \\
Prolonged pregnancy & $29(58)$ \\
Non-reassuring fetal heart rate & 0
\end{tabular}

Table 5. Obstetricians who would use misoprostol in conditions 1 - $6(N=50)$

\begin{tabular}{ll}
\hline Answer choices $^{*}$ & Responses, $\boldsymbol{n}$ (\%) \\
\hline Breech presentation & $3(6)$ \\
Multiple pregnancy & $9(18)$ \\
Cardiac disease & $19(38)$ \\
Impression of a big baby & $12(24)$ \\
Unconscious patient & $10(20)$ \\
Previous uterine incision & $3(6)$ \\
No use & $20(40)$ \\
${ }^{*}$ Most obstetricians would give misoprostol in cases of more than one of these conditions.
\end{tabular}

every $1-2$ hours, and the tendency was to use it mainly in those who were less than para 3 (Table 6). The Ministry of Health has distributed the WHO misoprostol dosing guidelines but they seem not to have been widely accepted, given the above findings. The departmental dosing schedule at Harare hospital is more dose intense than the WHO/FIGO/ NICE schedule of 20 - $25 \mu \mathrm{g}$ misoprostol 2-hourly. Most practitioners did not decrease the dose as parity increased although 10 practitioners stated they would completely avoid misoprostol in those with parities $>3$. The added caution does not seem to be justified as WHO/FIGO guidelines do not recommend against use in higher parities. It is possible that practitioners would settle for the safest, most efficacious and userfriendly dose. A user-friendly dosing schedule would be one with less dosing frequency, yet maintaining safety and efficacy.

It was surprising that three practitioners would use misoprostol in women with a previous caesarean section despite the inherent risk of uterine rupture, should hyperstimulation occur (Table 5). While there were no reported cases of uterine rupture in 160 women with a previous caesarean section in a Cochrane systematic review of oral misoprostol for induction of labour, most guidelines caution against using misoprostol in women with previous uterine surgery ${ }^{[1]}$

It is interesting and disturbing to note that only $62 \%$ of practitioners practise routine cervical assessment before prescribing misoprostol. 
Table 6. Dosing schedule according to parity $(N=50)$

\begin{tabular}{|c|c|c|c|c|c|c|}
\hline \multirow[b]{2}{*}{ Misoprostol dosing } & \multicolumn{6}{|c|}{ Parity, $n(\%)$} \\
\hline & $\mathbf{0}$ & 1 & 2 & 3 & 4 & $>4$ \\
\hline Other regimens & $13(26)$ & $15(30)$ & $15(30)$ & $19(18)$ & $19(38)$ & $17(34)$ \\
\hline $\begin{array}{l}20 \text { - } 30 \mu \mathrm{g} \text { stat, then } 15 \text { - } 20 \mu \mathrm{g} \text { hourly } \\
\text { (departmental recommendations) }\end{array}$ & $12(24)$ & $12(24)$ & $12(24)$ & $12(24)$ & $10(20)$ & $11(22)$ \\
\hline 20 - 25 g, 2-hourly (WHO/FIGO/NICE) & $10(20)$ & $10(20)$ & $10(20)$ & $10(20)$ & $10(20)$ & $10(20)$ \\
\hline $20-25 \mu \mathrm{g}$, hourly & $2(4)$ & $2(4)$ & $3(6)$ & $3(6)$ & $3(6)$ & $1(2)$ \\
\hline $50 \mu \mathrm{g}$ stat, then 4 - 6-hourly & $2(4)$ & $2(4)$ & $2(4)$ & $2(4)$ & $1(2)$ & $1(2)$ \\
\hline Vaginal & $2(4)$ & $1(2)$ & $1(2)$ & $1(2)$ & $1(2)$ & $1(2)$ \\
\hline No use & - & - & - & - & $3(6)$ & $7(14)$ \\
\hline
\end{tabular}

The argument might be that misoprostol still works whether the cervix is ripe or not but cervical assessment selects out candidates for immediate amniotomy. Amniotomy with or without oxytocin might be more expensive and more laborious than using misoprostol alone. However, cervical assessment allows for other interventions including membrane sweeping which can avoid unnecessary use of misoprostol or increase the chance of a successful induction.

\section{Study limitations}

This was an online survey and hence respondents had no chance to seek clarity on certain questions.

\section{Conclusion}

Obstetricians in Zimbabwe have adopted a variety of misoprostol dosing schedules other than the ones in standard protocols such as the WHO, FIGO or NICE guidelines. There was considerable difference of opinion concerning the conditions which contraindicate misoprostol use in term pregnancy, and also on the number of cycles of misoprostol to be administered.

1. Alfirevic Z, Aflaifel N, Weeks A. Oral misoprostol for induction of labour. Cochrane Database Sys Rev 2014;6:CD001338. https://doi.org/10.1002/14651858.CD001338.pub3

2. World Health Organization. WHO recommendations for induction of labour. Geneva: WHO, 2011. 3. Zvandasara P, Saungweme G, Mlambo J, Chidembo W, Madzivanzira N, Mwanjira C. Induction of labour with titrated oral misoprostol suspension. A comparative study with vaginal misoprostol. Cent Afr J Med 2008;54(9-12):43-49. https://doi.org/10.4314/cajm.v54i9-12.62626

4. Rahman H, Pradhan A, Kharka L, Renjhen P, Kar S, Dutta S. Comparative evaluation of 50 microgram oral misoprostol and 25 microgram intravaginal misoprostol for induction of labour at term. J Obstet Gynaecol Can 2013;35(5):408-416. https://doi.org/10.1016/s1701-2163(15)30931-2

5. National Institute for Health and Care Excellence. Clinical Guidelines: Inducing Labour. London: NICE, 2008. https://www.nice.org.uk/guidance/cg70 (accessed 12 February 2016).

6. Kundodyiwa TW, Alfirevic Z, Weeks AD. Low-dose oral misoprostol for induction of labour: A systematic review. Obstet Gynecol 2009;113(2 Pt 1):3743-3783. https://doi.org/10.1097/ aog.0b013e3181945859

7. Mateveke B, Chipato T, Guzha B, Mahachi L. Factors associated with failed induction of labour in patients undergoing induction with titrated oral misoprostol at Harare Maternity Hospital. Am Res J Gynecol 2015;1(1):12-16.

8. The National Medicine and Therapeutics Policy Advisory Committee (NMTPAC). 6th Essential Medicines List and Standard Treatment Guidelines for Zimbabwe. Harare: NMTPAC, 2011;93-95. http://apps.who.int/medicinedocs/documents/s21753en/s21753en.pdf (accessed 12 February 2016).

9. Department of Obstetrics and Gynaecology. Essential Guide to Management of Common Obstetric and Gynecologic Conditions in Zimbabwe. Harare: University of Zimbabwe, 2012(8):30-32. 